\title{
Biocomposite of Cassava Starch Reinforced with Cellulose Pulp Fibers Modified with Deposition of Silica $\left(\mathrm{SiO}_{2}\right)$ Nanoparticles
}

\author{
Joabel Raabe, ${ }^{1}$ Alessandra de Souza Fonseca, ${ }^{1}$ Lina Bufalino, ${ }^{1}$ \\ Caue Ribeiro, ${ }^{2}$ Maria Alice Martins, ${ }^{2}$ José Manoel Marconcini, ${ }^{2}$ \\ Lourival M. Mendes, ${ }^{1}$ and Gustavo Henrique Denzin Tonoli ${ }^{1}$ \\ ${ }^{1}$ Department of Forest Science (DCF), Universidade Federal de Lavras, P.O. Box 3037, 37200-000 Lavras, MG, Brazil \\ ${ }^{2}$ Laboratorio Nacional de Nanotecnologia para o Agronegocio (LNNA), Embrapa Instrumentacao, P.O. Box 741, \\ 13560-970 Sao Carlos, SP, Brazil \\ Correspondence should be addressed to Gustavo Henrique Denzin Tonoli; gustavotonoli@yahoo.com.br
}

Received 30 October 2014; Revised 27 January 2015; Accepted 29 January 2015

Academic Editor: Chuan Wang

Copyright (C) 2015 Joabel Raabe et al. This is an open access article distributed under the Creative Commons Attribution License, which permits unrestricted use, distribution, and reproduction in any medium, provided the original work is properly cited.

Eucalyptus pulp cellulose fibers were modified by the sol-gel process for $\mathrm{SiO}_{2}$ superficial deposition and used as reinforcement of thermoplastic starch (TPS). Cassava starch, glycerol, and water were added at the proportion of 60/26/14, respectively. For composites, $5 \%$ and $10 \%$ (by weight) of modified and unmodified pulp fibers were added before extrusion. The matrix and composites were submitted to thermal stability, tensile strength, moisture adsorption, and SEM analysis. Micrographs of the modified fibers revealed the presence of $\mathrm{SiO}_{2}$ nanoparticles on fiber surface. The addition of modified fibers improved tensile strength in $183 \%$ in relation to matrix, while moisture adsorption decreased $8.3 \%$. Such improvements were even more effective with unmodified fibers addition. This result was mainly attributed to poor interaction between modified fibers and TPS matrix detected by SEM analysis.

\section{Introduction}

Plant fibers have been studied as reinforcement in polymeric matrix in order to improve their physical and mechanical properties, as established practice for development of environmentally friendly products [1-8].

Starch is a promising material due to its high availability, renewable and biodegradable (even after being converted into a thermoplastic) character. Besides, this natural polymer presents interesting properties and characteristics for processing, being an attractive alternative to replace the synthetic polymers in applications that do not require long periods of use $[9,10]$. Beyond many advantages, it should be noticed that there are some challenges to be addressed concerning thermoplastic starch competitiveness to partially replace conventional materials, such as lower mechanical strength and elasticity, high permeability to gases, as well as high hygroscopicity, and significant lower mechanical properties after water uptake [11].

Some strategies have been tested in order to minimize the high hygroscopicity of the cellulose fibers and to improve the chemical compatibility between cellulose fibers and various polymeric matrices [12-14]. Modifications of fiber surface and structural properties are mainly based on the reactivity of the cellulose hydroxyls [13-16].

Hybrid organic-inorganic material was obtained in our previous work by deposition of $\mathrm{SiO}_{2}$ nanoparticles on cellulose fiber surface [17]. Such modification with nanoparticles decreased the moisture adsorption of the fibers by reducing the amount of free hydroxyl groups, as reported elsewhere $[18,19]$. Therefore, the aim of this study was to evaluate the feasibility of applying cellulose pulp fibers modified with silica $\left(\mathrm{SiO}_{2}\right)$ nanoparticles in thermoplastic starch (TPS). The thermal stability, tensile strength, and moisture adsorption of the composites were investigated.

\section{Materials and Methods}

2.1. Materials. Eucalyptus cellulose fibers were obtained from $\mathrm{kraft}$ pulping process, with average length of $0.81 \pm 0.01 \mathrm{~mm}$ and average width of $15.9 \pm 0.3 \mu \mathrm{m}$. Chemical composition of 
the fibers was cellulose (86.3\%), hemicelluloses $(12.9 \%)$, and ashes and extractives $(0.8 \%)$.

The inorganic precursor tetraethyl orthosilicate $\left(\mathrm{C}_{8} \mathrm{H}_{20} \mathrm{O}_{4} \mathrm{Si}\right.$-TEOS, 98\%) for $\mathrm{SiO}_{2}$ synthesis was provided by Sigma Aldrich. Ammonium hydroxide $\left(\mathrm{NH}_{4} \mathrm{OH}-30 \% \mathrm{v} \cdot \mathrm{v}^{-1}\right)$ was the catalyst. Ethanol $\left(\mathrm{CH}_{3} \mathrm{CH}_{2} \mathrm{OH}-\mathrm{Neon} 95 \%\right)$ was the solvent. Potassium sulfate $\left(\mathrm{K}_{2} \mathrm{SO}_{4}-\right.$ Vetec P.A.) was used for humidity control in the moisture adsorption test.

Cassava starch, composed of $85.5 \%$ amylopectin and $14.5 \%$ amylose (purchased from SM Ltda., Brazil); bidistilled glycerin plasticizer (Synth 98\%); stearic acid $\left(\mathrm{C}_{18} \mathrm{H}_{36} \mathrm{O}_{2}-\right.$ Synth 98\%); and anhydrous citric acid $\left(\mathrm{C}_{6} \mathrm{H}_{8} \mathrm{O}_{7}-\mathrm{Chenco}\right.$ 98\%) were used for preparation of the TPS extruded composites.

\subsection{Methods}

2.2.1. Modification of the Cellulose Fiber Surface. Unmodified cellulose fibers were kept in deionized water under mechanical stirring for $24 \mathrm{~h}$ in order to achieve total disintegration of cellulose sheets and proper fiber dispersion. Water to fiber consistency was $100 \mathrm{~mL} \cdot \mathrm{g}^{-1}$.

Fiber modification was carried out by sol-gel process based on previous studies [17-19]. A mass of $45 \mathrm{~g}$ of cellulose fibers was immersed in a solution composed of $3.6 \mathrm{~L}$ of ethanol, $405 \mathrm{~mL}$ of deionized water, and $67.5 \mathrm{~mL}$ of ammonium hydroxide. Constant and moderate mechanical stirring (300 rpm) was kept for $2 \mathrm{~h}$, after which $8.4 \mathrm{~g}$ of TEOS per $\mathrm{g}$ of cellulose fiber solution was slowly added drop by drop and a solution with fiber consistency of $100 \mathrm{~mL} \cdot \mathrm{g}^{-1}$ was prepared.

After addition of TEOS, the reaction was kept under stirring for $18 \mathrm{~h}$, under controlled environmental conditions (temperature of $20 \pm 2^{\circ} \mathrm{C}$ and relative humidity of $65 \pm 5 \%$ ). The modified fibers were thoroughly washed with deionized water, filtered, and subsequently dried at $60 \pm 2^{\circ} \mathrm{C}$ [17].

2.2.2. Processing of the Thermoplastic Starch (TPS) and Composites. The thermoplastic starch (TPS) was obtained from the physical mixture of cassava starch, glycerol, and deionized water in the mass proportions of $60 / 24 / 16$, respectively. The contents of $1 \%$ (by weight) of stearic acid and $1 \%$ (by weight) of citric acid were used as antioxidants for extrusion, according to previous studies [12, 20, 21]. Modified (MF$5 \%$ and $\mathrm{MF}-10 \%)$ and unmodified (NMF-5\% and NMF-10\%) fibers were added to the TPS at 5\% and 10\% loads (based on total mass of the composite). The composites were processed in an $18 \mathrm{~mm}$ corotating twin-screw with L/D ratio of 40 (Laboratory Extruder ZSK 18 MEGAlab, Coperion, Germany) equipped with seven heating zones and a ribbon die. The screw rotation speed was $250 \mathrm{rpm}$ and the temperature profile was set between 110 and $140^{\circ} \mathrm{C}$ in the seven heating zones. Extruded ribbons were pelletized and further processed in a single-screw extruder (AX Plásticos Ltda., Brazil) operating at $100 \mathrm{rpm}$ under $130^{\circ} \mathrm{C}, 130^{\circ} \mathrm{C}$, and $150^{\circ} \mathrm{C}$ heating zones for production of strips of $3 \mathrm{~mm}$ thickness. Tensile test samples were cut from these strips in a hydraulic press preheated for $2 \mathrm{~min}$ at $60^{\circ} \mathrm{C}$, with the aid of a metal mold with the dimensions described in ASTM 638-10 [22].
2.2.3. Scanning Electron Microscopy (SEM). Morphological characteristics of the fibers and the fractured surface of the composites were evaluated by SEM micrographs in a JEOL JSM-6510 microscope, with a tungsten filament and operating at $15 \mathrm{kV}$. An energy dispersive spectroscopy (EDS) system (model JEOL 6742A-Ultradry Silicon Drift) with an active area of $10 \mathrm{~mm}^{2}$ and $132 \mathrm{eV}$ resolution was used to detect and semiquantify $\mathrm{SiO}_{2}$ particles at the fiber surface. Average percentage of Si (\% by mass) was obtained after five scans per sample in a $1 \mu \mathrm{m}^{2}$ area. The fiber samples were bonded over a carbon tape on the metallic stubs and carbon coated (for EDS measurements) and gold coated (for scanning electron microscopy ( SEM) observations). Cryogenically fractured surfaces of the cross section of the test samples were prepared for microstructural evaluation by gold coating of the composites.

2.2.4. Thermogravimetric Analysis (TGA). Starch (in powder), plain TPS, and composites were subject to thermogravimetric analysis (TGA) in a TA Instruments analyzer (model Q500) as proposed in Tonoli et al. [23]. The 7-10 mg samples were heated in a Pt crucible from 25 to $600^{\circ} \mathrm{C}$ in a dynamic atmosphere of synthetic air $\left(80 \% \mathrm{~N}_{2}\right.$ and $\left.20 \% \mathrm{O}_{2}\right)$ flowing at $60 \mathrm{~mL} \cdot \mathrm{min}^{-1}$ and heating rate of $10^{\circ} \mathrm{C} \cdot \mathrm{min}^{-1}$. The critical weight loss temperatures ( $T$-onset), the temperature at which samples lost between 70 and $80 \%$ of mass ( $T$-shoulder), and the temperature at which the final mass became stable ( $T$ endset) were obtained from the TG curves.

2.2.5. Mechanical Properties (Tensile Test). Tensile tests of the TPS and composites were carried out according to ASTM D 638-10 [22], using universal testing machine (EMIC DL3000) with a $500 \mathrm{Kgf}$ load cell. The test speed was set to $50 \mathrm{~mm} \cdot \mathrm{min}^{-1}$ and the minimum of five replicates per composite material were tested in order to determine the Young modulus $(E)$, ultimate tensile strength $\left(\sigma_{r}\right)$, and deformation at break $\left(\varepsilon_{r}\right)$ of the materials.

2.2.6. Moisture Adsorption Analysis. Five $1.0 \mathrm{~cm} \times 4.0 \mathrm{~cm} \times$ $0.2 \mathrm{~cm}$ samples of each formulation were predried for $48 \mathrm{~h}$ at $60^{\circ} \mathrm{C}$, weighed, and placed in hermetically closed containers with $97 \pm 2 \%$ of relative humidity $(\mathrm{RH})$ and $20 \pm 2^{\circ} \mathrm{C}$, using a saturated potassium sulfate solution, as prescribed by the ASTM E104 [24] standard. The moisture adsorbed by the samples by time was determined by weighing $(0.0001 \mathrm{~g}$ precision) them at successive intervals until they reached constant weight. The amount of moisture adsorbed (MA) by the samples was calculated as follows:

$$
\operatorname{MA}(\%)=\left[\frac{\left(M_{t}-M_{0}\right)}{M_{0}}\right] \times 100
$$

where $M_{0}$ and $M_{t}$ are the initial mass of the sample (prior to exposure to moisture) and the sample mass after $t$ hours of exposure to moisture $(97 \pm 2 \% \mathrm{RH})$, respectively. Each data point represents an average of five samples. 


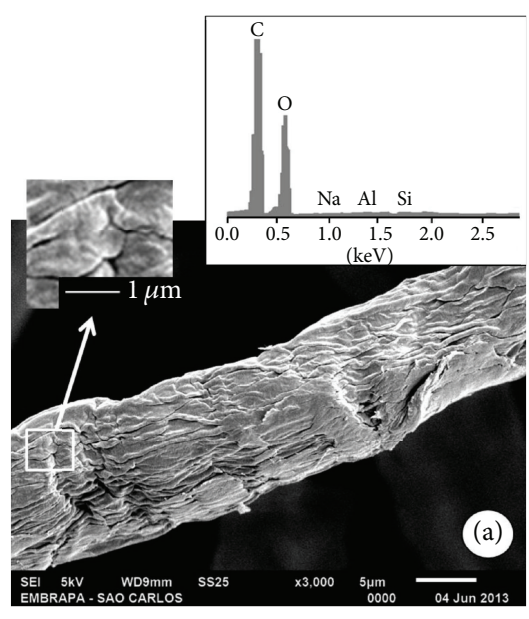

(a)

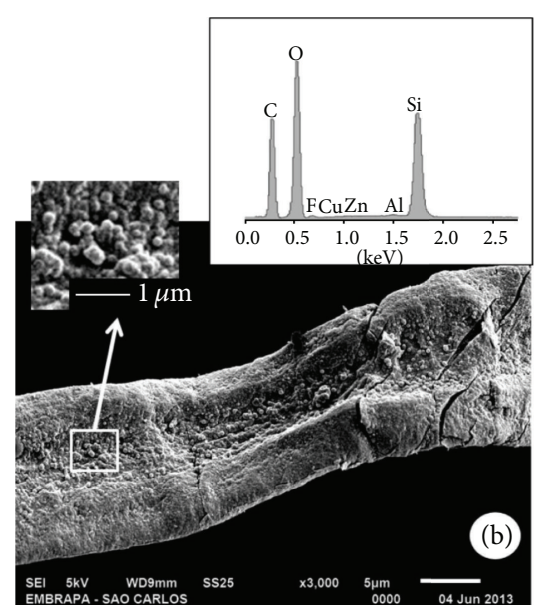

(b)

FIGURE 1: SEM micrographs and EDS measurements (detail) of (a) unmodified and (b) modified cellulose fibers.

\section{Results and Discussion}

3.1. Fiber Modification. Figure 1 shows SEM images and EDS analysis of unmodified and modified cellulose pulp fibers. Cellulose pulp fibers before modification (unmodified) showed a smooth and uniform surface (Figure 1(a)), with some apparent imperfections (detail) caused by the subsequent stages of drying during the pulping and bleaching process. The content of silicon ( $\mathrm{Si}$ ) in unmodified fibers $(1.4 \%)$ was clearly lower compared with the modified fiber $(17.7 \%)$, as seen in the peaks of EDS analysis (Figures 1(a) and 1(b), resp.). SEM and EDS of the modified fibers (Figure 1(b)) show that the $\mathrm{SiO}_{2}$ nanoparticles (detail) were deposited on the surface of the cellulose fibers, as observed by the increasing of the silicon $(\mathrm{Si})$ peak in the EDS measurement, confirming that the modification procedure was successful.

The deposition of $\mathrm{SiO}_{2}$ nanoparticles caused the coating of imperfections found in unmodified cellulose fibers. $\mathrm{SiO}_{2}$ deposition is achieved by the hydrolysis of the TEOS precursor and subsequent condensation of the resultant hydroxyl groups on the surface of the fibers $[17,25]$. Although no information was available from EDS measurements about the thickness or degree of $\mathrm{SiO}_{2}$ covering, the results strongly suggest that a hybrid cellulose $+\mathrm{SiO}_{2}$ composite was formed since $\mathrm{Si}$ peak was remarkably intense in relation to $\mathrm{C}$ and $O$ peaks [26]. Pinto et al. [18] succeeded in cellulose fibers modification by using TEOS precursor. The authors reported fibers coated with a homogeneous layer of $\mathrm{SiO}_{2}$ nanoparticles, which provided a remarkable reduction in water uptake. Ashori et al. [19] conducted a similar work with bacterial cellulose and observed strong chemical interactions between cellulose and silica phases in addition to improvement of the composite mechanical strength. The above-mentioned studies clearly show the effectiveness of using TEOS precursor in the modification of cellulose fibers.

The moisture adsorption pattern of the unmodified and modified cellulose fibers exposed to $97 \pm 2 \% \mathrm{RH}$ is shown in Figure 2. After mass stabilization was reached, the unmodified fibers presented higher moisture adsorption $(25.0 \pm 0.5 \%)$

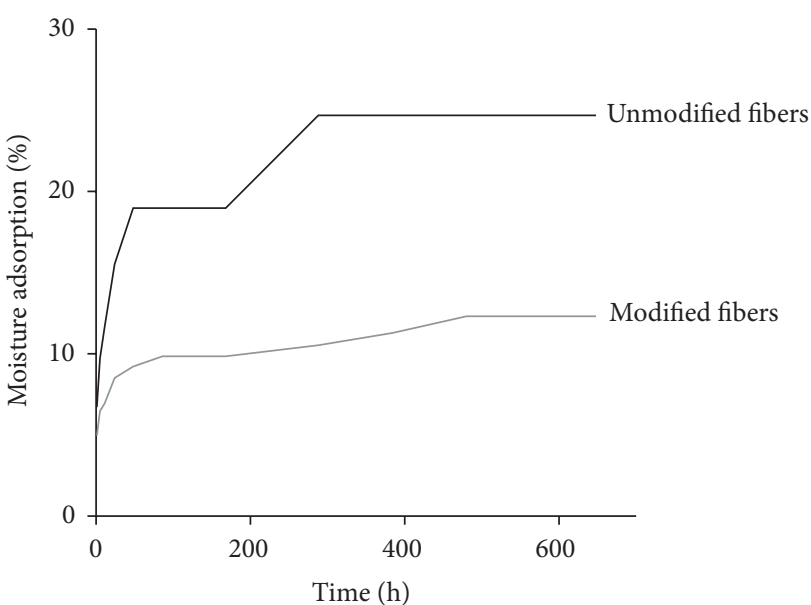

FIGURE 2: Moisture adsorption of unmodified and modified fibers.

than modified fibers $(12.3 \pm 1.0 \%)$. This result is attributed to the decrease of free hydroxyls, caused by deposition of $\mathrm{SiO}_{2}$ nanoparticles on the surface of the fibers, reducing their hygroscopicity.

3.2. Thermal Analysis of the Composites. The thermal behaviors (TG and DTG) of the starch, TPS, and composites reinforced with modified fibers (MF) and unmodified (NMF) fibers are shown in Figure 3. For starch, there were three stages of mass loss clearly defined in TG curves. Steps two and three as much as main peaks are readily observed in DTG curves. The first occurred between $30^{\circ} \mathrm{C}$ and $150^{\circ} \mathrm{C}$, corresponding to release of water and volatile. The second was observed between 250 and $350^{\circ} \mathrm{C}$ with most prominent degradation at $310^{\circ} \mathrm{C}$ related to starch decomposition [27]. Some gases such as $\mathrm{CO}_{2}, \mathrm{CO}, \mathrm{H}_{2} \mathrm{O}$, and other small volatile are released during this stage along with carbonaceous residue formation $[28,29]$. The last stage took place between 415 and $540^{\circ} \mathrm{C}$ and corresponds to decomposition of 


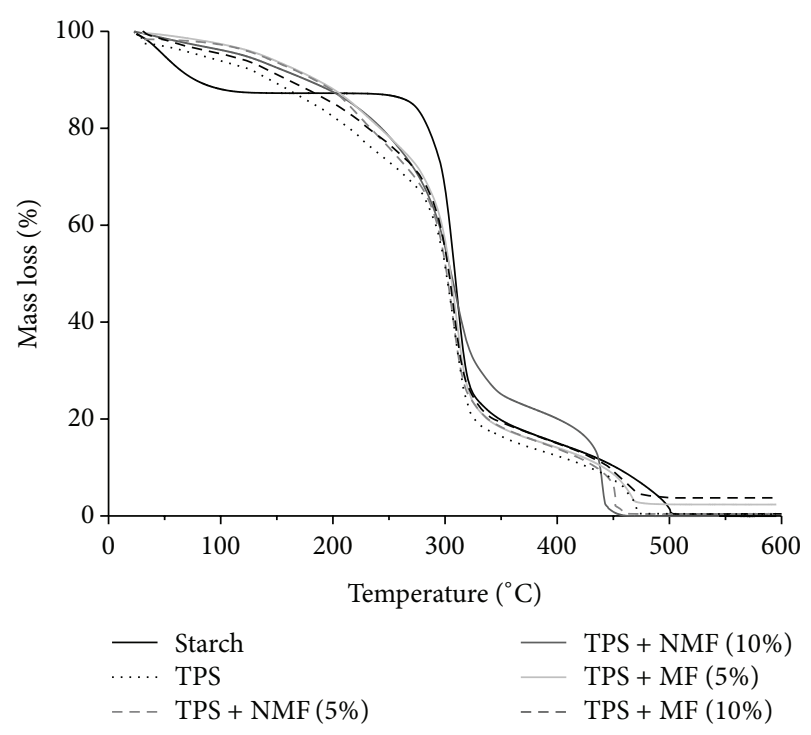

(a)

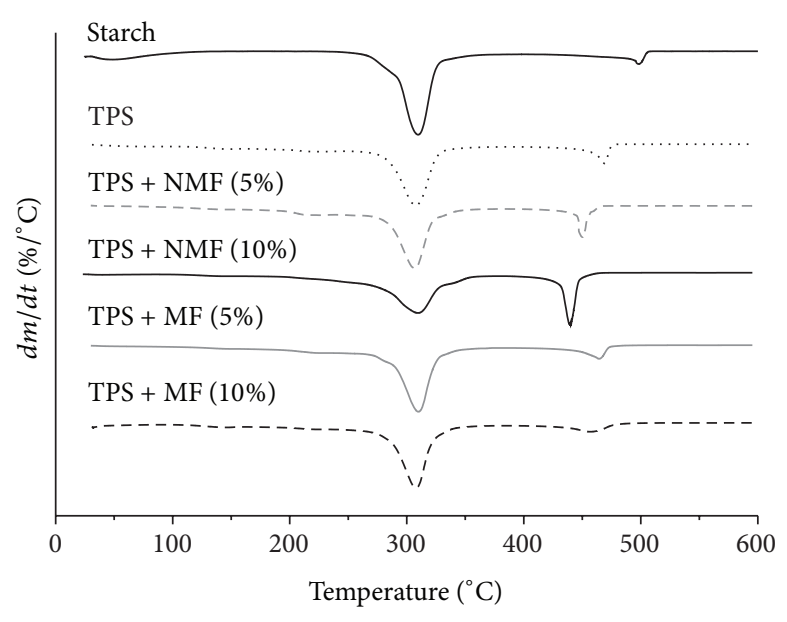

(b)

FIGURE 3: (a) TG and (b) DTG of the starch (powder), TPS, and composites reinforced with unmodified (NMF) and modified (MF) cellulose fibers. Analysis ran under synthetic air atmosphere.

TABLE 1: Thermal properties (obtained by TG and DTG analyses) of the starch, TPS, and composites.

\begin{tabular}{lccccc}
\hline Sample & $T$-onset $\left({ }^{\circ} \mathrm{C}\right)$ & DTG peak $\left({ }^{\circ} \mathrm{C}\right)$ & $T$-shoulder $\left({ }^{\circ} \mathrm{C}\right)$ & $T$-endset $\left({ }^{\circ} \mathrm{C}\right)$ & Residue at $600^{\circ} \mathrm{C}(\%)$ \\
\hline Starch & $300 \pm 7$ & $310 \pm 3$ & $321 \pm 6$ & $502 \pm 2$ & $0.4 \pm 0.3$ \\
TPS & $291 \pm 11$ & $308 \pm 1$ & $321 \pm 10$ & $471 \pm 4$ & $0.4 \pm 0.2$ \\
TPS + NMF (5\%) & $290 \pm 3$ & $307 \pm 3$ & $320 \pm 7$ & $459 \pm 2$ & $0.4 \pm 0.4$ \\
TPS + NMF (10\%) & $291 \pm 3$ & $309 \pm 2$ & $325 \pm 16$ & $443 \pm 2$ & $0.0 \pm 0.5$ \\
TPS + MF (5\%) & $293 \pm 4$ & $310 \pm 3$ & $322 \pm 6$ & $475 \pm 7$ & $2.4 \pm 2.2$ \\
TPS + MF (10\%) & $292 \pm 6$ & $308 \pm 3$ & $320 \pm 10$ & $471 \pm 2$ & $3.7 \pm 1.8$ \\
\hline
\end{tabular}

the previously formed residue since an oxidative atmosphere was used [27].

TPS exhibited a steady loss of weight from room temperature to near $250^{\circ} \mathrm{C}$. This behavior is related to both the release of water adsorbed by the plastics during their acclimatization and combustion/volatilization of glycerol. This phenomenon hinders distinction between the first and second stage of TPS degradation and causes stronger mass loss ratio in the first stage in comparison to starch [30].

From the TG curve (Figure 3(a)), the initial ( $T$-onset) and end ( $T$-endset) degradation temperatures of starch, TPS, and composite formulations were determined (Table 1). TPS and composites showed a slight anticipation of the main weight loss event $\left(\sim 290^{\circ} \mathrm{C}\right)$ compared to starch granules $\left(\sim 300^{\circ} \mathrm{C}\right)$. This difference can be explained based on starch polymer chain fragmentation, due to TPS processing, by which organizational structure of the starch was partially destroyed causing the mobility of polymer chains to increase [3133]. Fiber addition (both NMF and MF) slightly decreased weight loss ratio for temperatures below $250^{\circ} \mathrm{C}$. NMF and MF levels were not greatly affected and the initial degradation temperature (Table 1, view $T$-onset) was similar for both TPS and composites. It is well known that unbleached fiber addition improves the thermal stability of the starch matrix when good adhesion between the parts is achieved [34]. Such behavior was not observed in this work.

Figure 3(b) shows the maximum DTG peak between 250 and $350^{\circ} \mathrm{C}$, which occurs around $310^{\circ} \mathrm{C}$ for all materials (Table 1). In addition, it can be noticed that starch exhibited the highest mass loss peak. The last thermal event after $400^{\circ} \mathrm{C}$ shows the decomposition of the carbonaceous residue that ranged from $498^{\circ} \mathrm{C}$ for starch to $467^{\circ} \mathrm{C}$ for TPS. Also, the increase in cellulose pulp load from $5 \%$ to $10 \%$ led to the decrease in temperature of maximum mass loss (from $450^{\circ} \mathrm{C}$ to $440^{\circ} \mathrm{C}$ for unmodified fibers and from $464^{\circ} \mathrm{C}$ to $456^{\circ} \mathrm{C}$ for modified fibers). This result suggests that cellulose and $\mathrm{Si}$ have a catalytic activity on the thermal decomposition of the starch carbonaceous product [27]. The residue contents remarkably raised with fiber load increase from 5 to $10 \%$, as much as from unmodified to $\mathrm{SiO}_{2}$ modified fibers.

3.3. Mechanical Performance of the Composites. The stress to strain curves for tensile test of TPS and composites is shown in Figure 4. All curves showed a linear region at low stress application, where the stress was proportional to the strain (elastic behavior), followed by plastic behavior and restriction, where the stress showed a constant pattern until failure. 


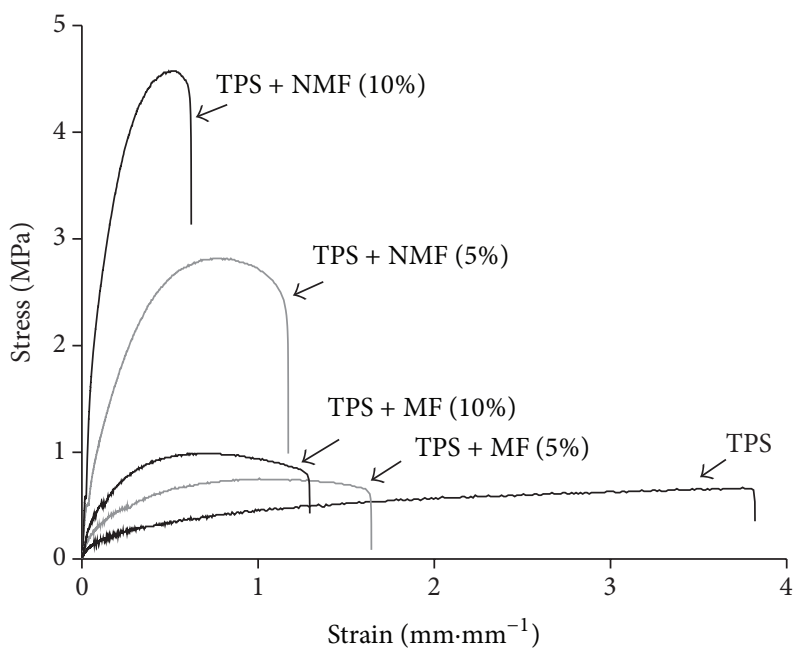

FIGURE 4: Stress to strain curves for tensile test of the TPS and composites reinforced with unmodified (NMF) and modified (MF) fibers.

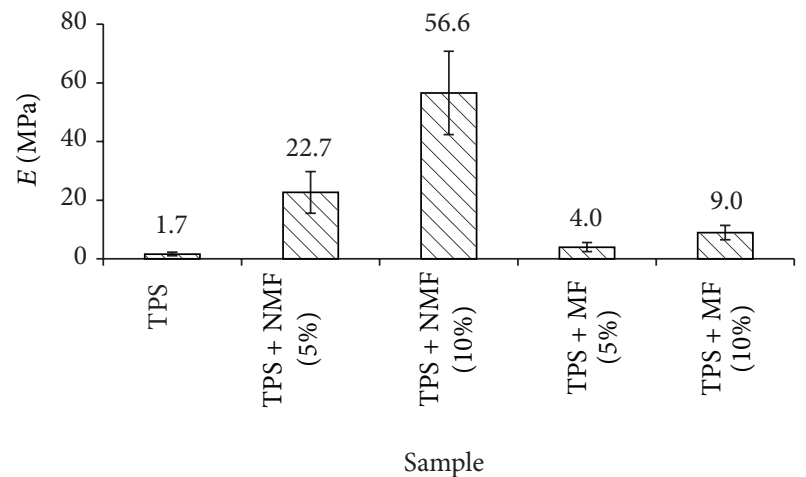

(a)

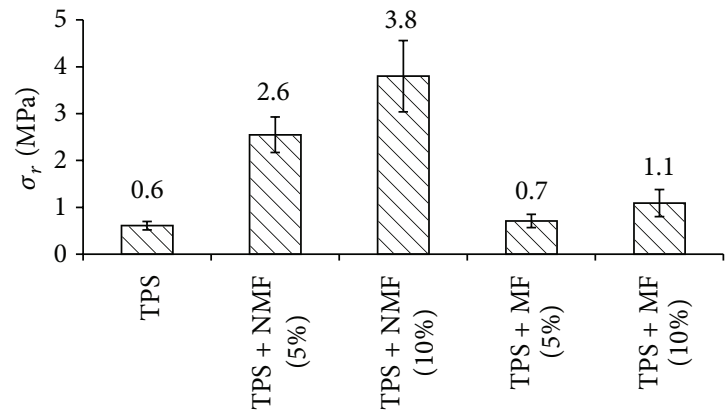

Sample

(b)

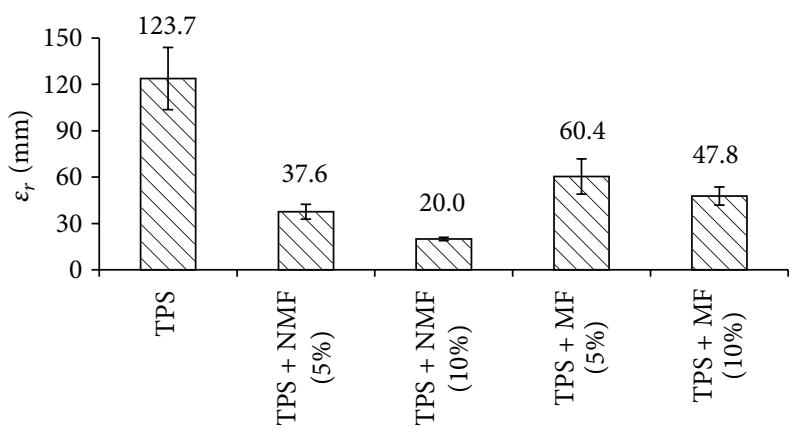

Sample

(c)

FIGURE 5: (a) Young modulus $(E)$, (b) tensile strength $\left(\sigma_{r}\right)$, and (c) strain at break $\left(\varepsilon_{r}\right)$ of TPS and composites reinforced with unmodified (NMF) and modified (MF) fibers.

Inclusion of cellulose fibers and increase in fiber load led to an increase of Young modulus $(E)$ and tensile strength $\left(\sigma_{r}\right)$ of the composites in comparison to the TPS. Nevertheless, the strain at break $\left(\varepsilon_{r}\right)$ decreased more than $50 \%$ with fiber addition (Figure 5).

Addition of 5\% of unmodified fibers to TPS increased in $1335 \%$ and $433 \%$ Young modulus and tensile strength, respectively. Inclusion of $10 \%$ of unmodified fibers to TPS increased in 3329\% and 633\% Young modulus and tensile strength, respectively. The improvement of the mechanical properties (tensile) with inclusion of different plant fibers and nanofibers in TPS composites was widely reported in literature $[10,35,36]$. For composites with modified fibers, the inclusion of $5 \%$ of fibers increased in $235 \%$ and $116 \%$ 


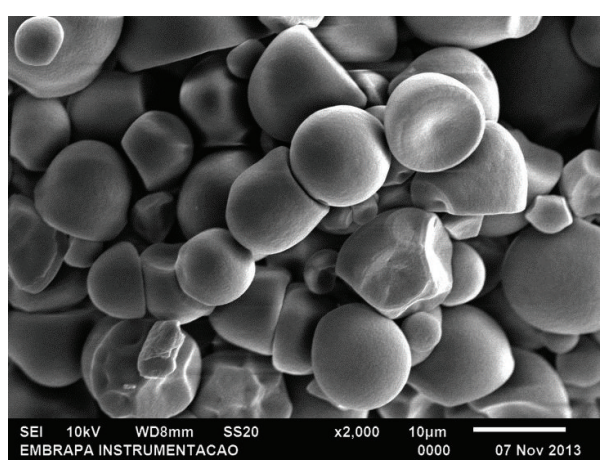

(a)

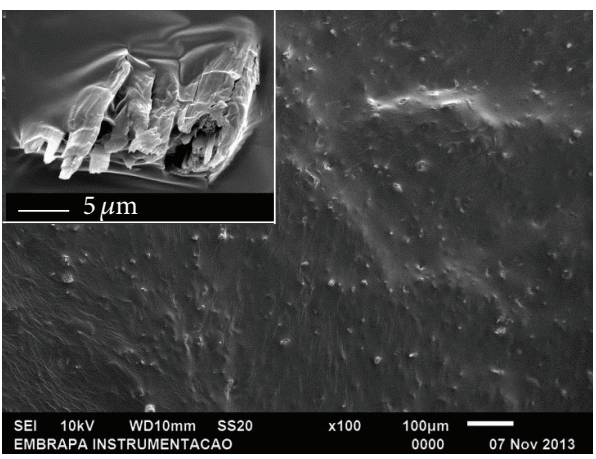

(c)

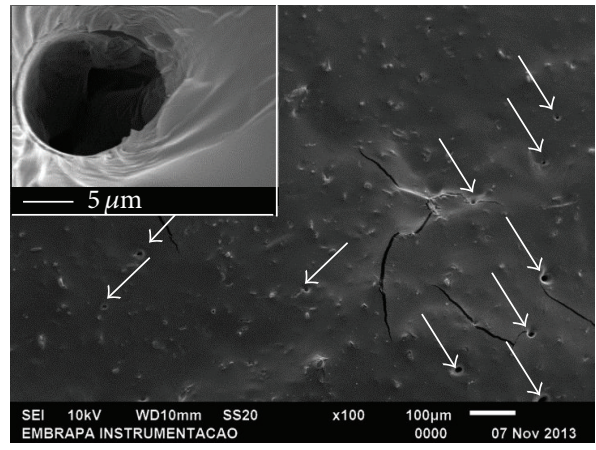

(e)

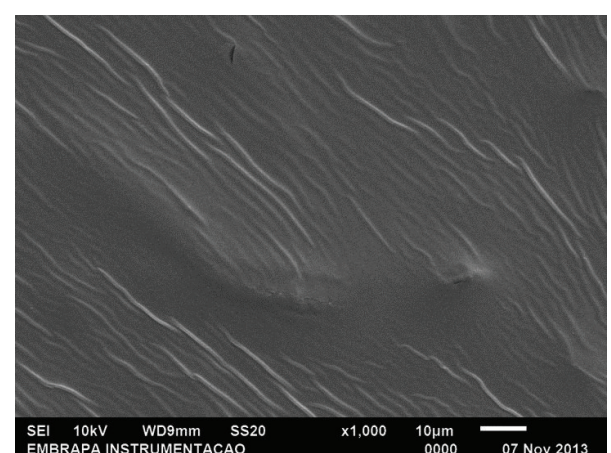

(b)

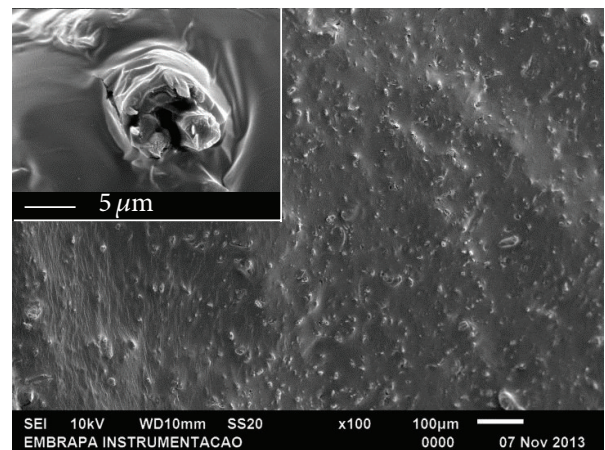

(d)

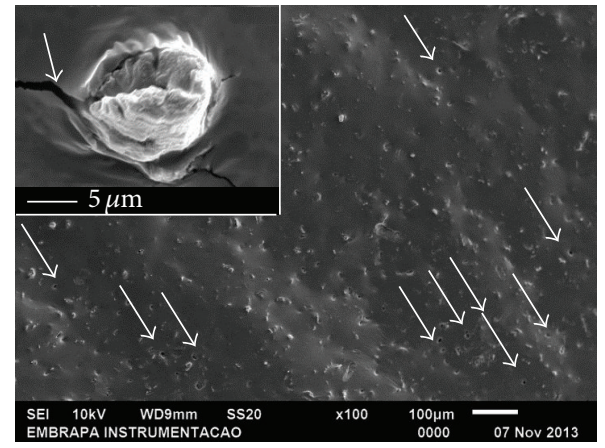

(f)

FIGURE 6: SEM micrographs of (a) raw starch; fractured surface of the (b) TPS; (c, d) composites reinforced with 5\% and 10\% of unmodified fibers (NMF), respectively; and (e,f) composites reinforced with $5 \%$ and $10 \%$ of modified fibers (MF). Arrows indicate holes in the composite after rupture.

the Young modulus and the tensile strength, respectively, while for $10 \%$ of fibers the increase was of $529 \%$ in the Young modulus and $183 \%$ in the tensile strength. The lower mechanical performance of composites reinforced with MF, in relation to NMF (unmodified) fibers, can be attributed to the poor adhesion of these fibers to the TPS matrix. $\mathrm{SiO}_{2}$ nanoparticles deposition on fiber surface drastically reduces the free hydroxyl groups [25], making them into hydrophobic. Fewer free hydroxyl groups on fiber surface hinder their interaction with the matrix, which strongly affects mechanical performance $[13,14]$. Effective wetting, uniform dispersion of all the components in the matrix, and strong interfacial adhesion are required to obtain high strength composites [37].
3.4. Microstructural Analyses of the Composites. Scanning electron microscopy (SEM) was used to observe the interaction and dispersion of the cellulose fibers in the TPS matrix. Micrographs of the starch powder and fractured surface of TPS and composites are depicted in Figure 6. The size of the starch granules was about 8 to $15 \mu \mathrm{m}$ (Figure 6(a)) and their complete breakage due to extrusion can be observed in the TPS and composites.

The fractured surface of the TPS samples (Figure 6(b)) shows homogeneous and compact structure, besides no visible flaws and voids. TPS composites reinforced with unmodified fibers (5\% and 10\% of NMF, Figures 6(c) and 6(d), resp.) show good fiber dispersion in the TPS matrix, without evident agglutinations. Strong interaction between 


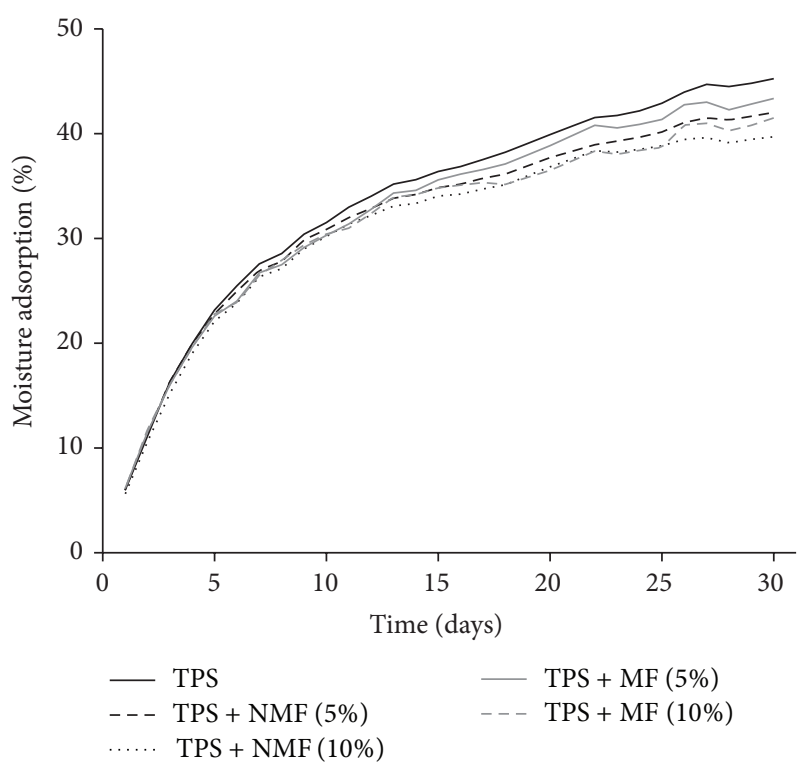

FIGURE 7: Moisture adsorption of the TPS and composites reinforced with unmodified (NMF) and modified (MF) fibers.

matrix and fibers was also observed (Figures 6(c) and 6(d) and details). SEM images evidence higher concentration of fibers in composites made with 10\% of NMF (Figure 6(d)) in comparison to those with 5\% NMF addition (Figure 6(c)). The same may be observed for composites with MF (Figures 6(e) and 6(f)). Fiber agglutinations are not desired because they limit the stresses transference from matrix to the fiber [38] and hence decrease mechanical strength of the composites. For composites reinforced with modified fibers it can be observed that fibers were pulled out from the TPS with fracture, leaving voids in the matrix (arrows in Figures 6(e) and $6(\mathrm{f})$ ). Certainly this is a result of ineffective interaction between composite phases (details in Figures 6(e) and 6(f)) as stated elsewhere [39].

3.5. Moisture Adsorption of Composites. The TPS adsorbs moisture due to its hydrophilic nature [40], which directly affects applications of derivate products. The moisture adsorption curve of the materials during 30 days of exposure to $97 \pm 2 \% \mathrm{RH}\left(20 \pm 2^{\circ} \mathrm{C}\right)$ is shown in Figure 7 . The moisture uptake in the TPS and composites increased linearly up to five days, followed by a slower adsorption ratio.

The addition of cellulose fibers contributed to decreasing of moisture adsorption of TPS (Figure 7), similarly to results from other works [41-43]. Remarkable differences in water resistance among the evaluated materials become evident after the fifth day of exposure to humid environment. After 30 days, it was observed a reduction of $12.3 \%$ in moisture adsorption for composites reinforced with 10\% NMF, in comparison to TPS. The composites reinforced with 5\% and $10 \%$ of MF presented $4.2 \%$ and $8.3 \%$ decrease in water adsorption, respectively, in relation to TPS.

Lower enhancement of moisture adsorption found for composites reinforced with $\mathrm{MF}$ is possibly due to formation of microcracks at the interface between phases (arrow in the detail of Figure 6(f)), which may favor moisture accumulation. Interactions by hydrogen bonding between starch molecules and cellulose fibers for both modified and unmodified fibers make composites more stable to humid conditions in relation to TPS [44].

Main results found in our work show that deposition of $\mathrm{SiO}_{2}$ nanoparticles hindered the interfacial interaction between the cellulosic fibers and the TPS matrix. Future investigations with nonpolar matrices are recommended to advance the development of composites reinforced with the hybrid $\mathrm{SiO}_{2}$-cellulose materials proposed in this work, since a remarkable decrease in hydrophilic nature of cellulose fibers was achieved.

\section{Conclusions}

The main proposition of this work was to develop a new high strength composite made from TPS and Eucalyptus cellulose pulp fibers modified by $\mathrm{SiO}_{2}$ nanoparticles superficial deposition. Improvements include the moisture adsorption decrease and higher thermal stability of composites in relation to TPS. Higher cellulose fiber load (10\%) provided improvements in mechanical and moisture strength of the composites. Poorer interaction between composite phases was detected when modified fibers (MF) were used; hence higher strength was found for formulations with unmodified fibers. The modification of the fibers proposed in this work was successful, since a distinct surface characteristic of the cellulose pulp fibers was observed. Such modification is very promising for ongoing investigations towards development and improvement of renewable composites.

\section{Conflict of Interests}

The authors declare that there is no conflict of interests regarding the publication of this paper.

\section{Acknowledgments}

Financial support for this research project was provided by the Conselho Nacional de Desenvolvimento Científico e Tecnológico (CNPq), Fundação de Amparo à Pesquisa do Estado de São Paulo (Fapesp), Fundação de Amparo à Pesquisa do Estado de Minas Gerais (Fapemig), Coordenação de Aperfeiçoamento de Pessoa de Nível Superior (Capes, Edital Capes-Embrapa), and Empresa Brasileira de Pesquisa Agropecuária (Embrapa), in Brazil. Thanks also go to Rede Brasileira de Compósitos e Nanocompósitos Lignocelulósicos (Religar).

\section{References}

[1] C. A. Hemais, "Polímeros e a indústria automobilística," Polímeros: ciência e tecnologia, vol. 13, no. 2, pp. 107-114, 2003.

[2] S. V. Joshi, L. T. Drzal, A. K. Mohanty, and S. Arora, "Are natural fiber composites environmentally superior to glass fiber reinforced composites?" Composites Part A: Applied Science and Manufacturing, vol. 35, no. 3, pp. 371-376, 2004. 
[3] F. N. P. Nicolai, V. R. Botaro, and V. F. C. Lins, "Effect of saline degradation on the mechanical properties of vinyl ester matrix composites reinforced with glass and natural fibers," Journal of Applied Polymer Science, vol. 108, no. 4, pp. 2494-2502, 2008.

[4] A. Alemdar and M. Sain, "Biocomposites from wheat straw nanofibers: morphology, thermal and mechanical properties," Composites Science and Technology, vol. 68, no. 2, pp. 557-565, 2008.

[5] A. Ashori, "Wood-plastic composites as promising greencomposites for automotive industries!, Bioresource Technology, vol. 99, no. 11, pp. 4661-4667, 2008.

[6] Y. Xue, Y. Du, S. Elder, K. Wang, and J. Zhang, “Temperature and loading rate effects on tensile properties of kenaf bast fiber bundles and composites," Composites Part B: Engineering, vol. 40, no. 3, pp. 189-196, 2009.

[7] A. S. Fonseca, F. A. Mori, G. H. D. Tonoli, H. Savastano, D. L. Ferrari, and I. P. A. Miranda, "Properties of an Amazonian vegetable fiber as a potential reinforcing material," Industrial Crops and Products, vol. 47, pp. 43-50, 2013.

[8] A. R. Kakroodi, S. Cheng, M. Sain, and A. Asiri, "Mechanical, thermal, and morphological properties of nanocomposites based on polyvinyl alcohol and cellulose nanofiber from Aloe vera rind," Journal of Nanomaterials, vol. 2014, Article ID 903498, 7 pages, 2014.

[9] R. Belhassen, F. Vilaseca, P. Mutjé, and S. Boufi, “Thermoplasticized starch modified by reactive blending with epoxidized soybean oil," Industrial Crops and Products, vol. 53, pp. 261-267, 2014.

[10] M. G. Lomelí-Ramírez, S. G. Kestur, R. Manríquez-González, S. Iwakiri, G. B. De Muniz, and T. S. Flores-Sahagun, "Biocomposites of cassava starch-green coconut fiber: part IIstructure and properties," Carbohydrate Polymers, vol. 102, no. 1, pp. 576-583, 2014.

[11] M. A. Huneault and H. Li, "Morphology and properties of compatibilized polylactide/thermoplastic starch blends," Polymer, vol. 48, no. 1, pp. 270-280, 2007.

[12] A. de Campos, G. H. D. Tonoli, J. M. Marconcini et al., "TPS/PCL composite reinforced with treated sisal fibers: property, biodegradation and water-absorption," Journal of Polymers and the Environment, vol. 21, no. 1, pp. 1-7, 2013.

[13] O. Faruk, A. K. Bledzki, H.-P. Fink, and M. Sain, "Biocomposites reinforced with natural fibers: 2000-2010," Progress in Polymer Science, vol. 37, no. 11, pp. 1552-1596, 2012.

[14] M. M. Kabir, H. Wang, K. T. Lau, and F. Cardona, "Chemical treatments on plant-based natural fibre reinforced polymer composites: an overview," Composites Part B: Engineering, vol. 43, no. 7, pp. 2883-2892, 2012.

[15] H. Liu, F. Xie, L. Yu, L. Chen, and L. Li, “Thermal processing of starch-based polymers," Progress in Polymer Science, vol. 34, no. 12, pp. 1348-1368, 2009.

[16] P. A. Skreekumar, J. Kuruvilla, G. Unnikrishnan, and T. Sabu, "Surface-modified sisal fiber-reinforced eco-friendly composites: mechanical, thermal, and diffusion studies," Polymer Composites, vol. 32, no. 1, pp. 131-138, 2011.

[17] J. Raabe, A. S. Fonseca, L. Bufalino et al., "Evaluation of reaction factors for deposition of silica $\left(\mathrm{SiO}_{2}\right)$ nanoparticles on cellulose fibers," Carbohydrate Polymers, vol. 114, pp. 424-431, 2014.

[18] R. J. B. Pinto, P. A. A. P. Marques, A. M. Barros-Timmons, T. Trindade, and C. P. Neto, "Novel $\mathrm{SiO}_{2} /$ cellulose nanocomposites obtained by in situ synthesis and via polyelectrolytes assembly," Composites Science and Technology, vol. 68, no. 3-4, pp. 10881093, 2008.
[19] A. Ashori, S. Sheykhnazari, T. Tabarsa, A. Shakeri, and M. Golalipour, "Bacterial cellulose/silica nanocomposites: preparation and characterization," Carbohydrate Polymers, vol. 90, no. 1, pp. 413-418, 2012.

[20] A. Campos, K. B. R. Teodoro, J. M. Marconcini, L. H. C. Mattoso, and S. M. Martins-Franchetti, "Efeito do tratamento das fibras nas propriedades do biocompósito de amido termoplástico/policaprolactona/sisal," Polímeros, vol. 21, no. 3, pp. 217-222, 2011.

[21] V. B. Carmona, A. De Campos, J. M. Marconcini, and L. H. C. Mattoso, "Kinetics of thermal degradation applied to biocomposites with TPS, PCL and sisal fibers by non-isothermal procedures," Journal of Thermal Analysis and Calorimetry, vol. 115, no. 1, pp. 153-160, 2014.

[22] ASTM D638-10, "Standard test for tensile properties of plastics," Annual book of ASTM standards, 2010.

[23] G. H. D. Tonoli, E. M. Teixeira, A. C. Corrêa et al., "Cellulose micro/nanofibres from Eucalyptus kraft pulp: preparation and properties," Carbohydrate Polymers, vol. 89, no. 1, pp. 80-88, 2012.

[24] ASTM E104-12, "Standard practice for maintaining constant humidity bymeans of aqueous solutions," Annual book of ASTM standards, 2012.

[25] B. P. Tripathi and V. K. Shahi, "Organic-inorganic nanocomposite polymer electrolyte membranes for fuel cell applications," Progress in Polymer Science, vol. 36, no. 7, pp. 945-979, 2011.

[26] G. H. D. Tonoli, U. P. Rodrigues Filho, H. Savastano Jr., J. Bras, M. N. Belgacem, and F. A. Rocco Lahr, "Cellulose modified fibres in cement based composites," Composites Part A: Applied Science and Manufacturing, vol. 40, no. 12, pp. 2046-2053, 2009.

[27] F. K. V. Moreira, D. C. A. Pedro, G. M. Glenn, J. M. Marconcini, and L. H. C. Mattoso, "Brucite nanoplates reinforced starch bionanocomposites," Carbohydrate Polymers, vol. 92, no. 2, pp. 1743-1751, 2013.

[28] C. T. Greenwood, "The thermal degradation of starch.," Advances in Carbohydrate Chemistry and Biochemistry, vol. 22, pp. 483-515, 1967.

[29] X. Zhang, J. Golding, and I. Burgar, "Thermal decomposition chemistry of starch studied by $13 \mathrm{C}$ high-resolution solid-state NMR spectroscopy," Polymer, vol. 43, no. 22, pp. 5791-5796, 2002.

[30] J. K. Pandey and R. P. Singh, "Green nanocomposites from renewable resources: effect of plasticizer on the structure and material properties of clay-filled starch," Starch, vol. 57, no. 1, pp. 8-15, 2005.

[31] P. Aggarwal, D. Dollimore, and K. Heon, "Comparative thermal analysis study of two biopolymers, starch and cellulose," Journal of Thermal Analysis, vol. 50, no. 1-2, pp. 7-17, 1997.

[32] P. Aggarwal and D. Dollimore, "A thermal analysis investigation of partially hydrolyzed starch," Thermochimica Acta, vol. 319, no. 1-2, pp. 17-25, 1998.

[33] A. Vasquez, V. P. Cyras, V. A. Alvarez, and J. I. Moran, "Starch/clay nano-biocomposites," in Environmental Silicate Nano-Biocomposites, L. Avérous and E. Pollet, Eds., chapter 11.14, pp. 287-321, Springer, London, UK, 1st edition, 2012.

[34] T. Phattaraporn, S. Waranyou, A. Fazilah, and W. Thawien, "Characterization and properties of rice starch films reinforced with palm press fibers," International Food Research Journal, vol. 17 , pp. 537-547, 2010.

[35] M. Hietala, A. P. Mathew, and K. Oksman, "Bionanocomposites of thermoplastic starch and cellulose nanofibers manufactured 
using twin-screw extrusion," European Polymer Journal, vol. 49, no. 4, pp. 950-956, 2013.

[36] J. P. López, P. Mutjé, A. J. F. Carvalho, A. A. S. Curvelo, and J. Gironès, "Newspaper fiber-reinforced thermoplastic starch biocomposites obtained by melt processing: evaluation of the mechanical, thermal and water sorption properties," Industrial Crops and Products, vol. 44, pp. 300-305, 2013.

[37] C. S. Wu, F. S. Yen, and C. Y. Wang, "Polyester/natural fiber biocomposites: preparation, characterization, and biodegradability," Polymer Bulletin, vol. 67, no. 8, pp. 1605-1619, 2011.

[38] M. F. Rosa, B.-S. Chiou, E. S. Medeiros et al., "Biodegradable composites based on starch/EVOH/glycerol blends and coconut fibers," Journal of Applied Polymer Science, vol. 111, no. 2, pp. 612618, 2009.

[39] C. A. Teacă, R. Bodîrlău, and I. Spiridon, "Effect of cellulose reinforcement on the properties of organic acid modified starch microparticles/plasticized starch bio-composite films," Carbohydrate Polymers, vol. 93, no. 1, pp. 307-315, 2013.

[40] D. Preechawong, M. Peesan, P. Supaphol, and R. Rujiravanit, "Characterization of starch/poly( $\varepsilon$-caprolactone) hybrid foams," Polymer Testing, vol. 23, no. 6, pp. 651-657, 2004.

[41] N. Soykeabkaew, N. Laosat, A. Ngaokla, N. Yodsuwan, and T. Tunkasiri, "Reinforcing potential of micro- and nano-sized fibers in the starch-based biocomposites," Composites Science and Technology, vol. 72, no. 7, pp. 845-852, 2012.

[42] V. A. Alvarez, R. A. Ruscekaite, and A. Vázquez, "Mechanical properties and water absorption behavior of composites made from a biodegradable matrix and alkaline-treated sisal fibers," Journal of Composite Materials, vol. 37, no. 17, pp. 1575-1588, 2003.

[43] V. A. Alvarez, R. A. Ruseckaite, and A. Vázquez, "Degradation of sisal fibre/Mater Bi-Y biocomposites buried in soil," Polymer Degradation and Stability, vol. 91, no. 12, pp. 3156-3162, 2006.

[44] Y. Lu, L. Weng, and X. Cao, "Biocomposites of plasticized starch reinforced with cellulose crystallites from cottonseed linter," Macromolecular Bioscience, vol. 5, no. 11, pp. 1101-1107, 2005. 

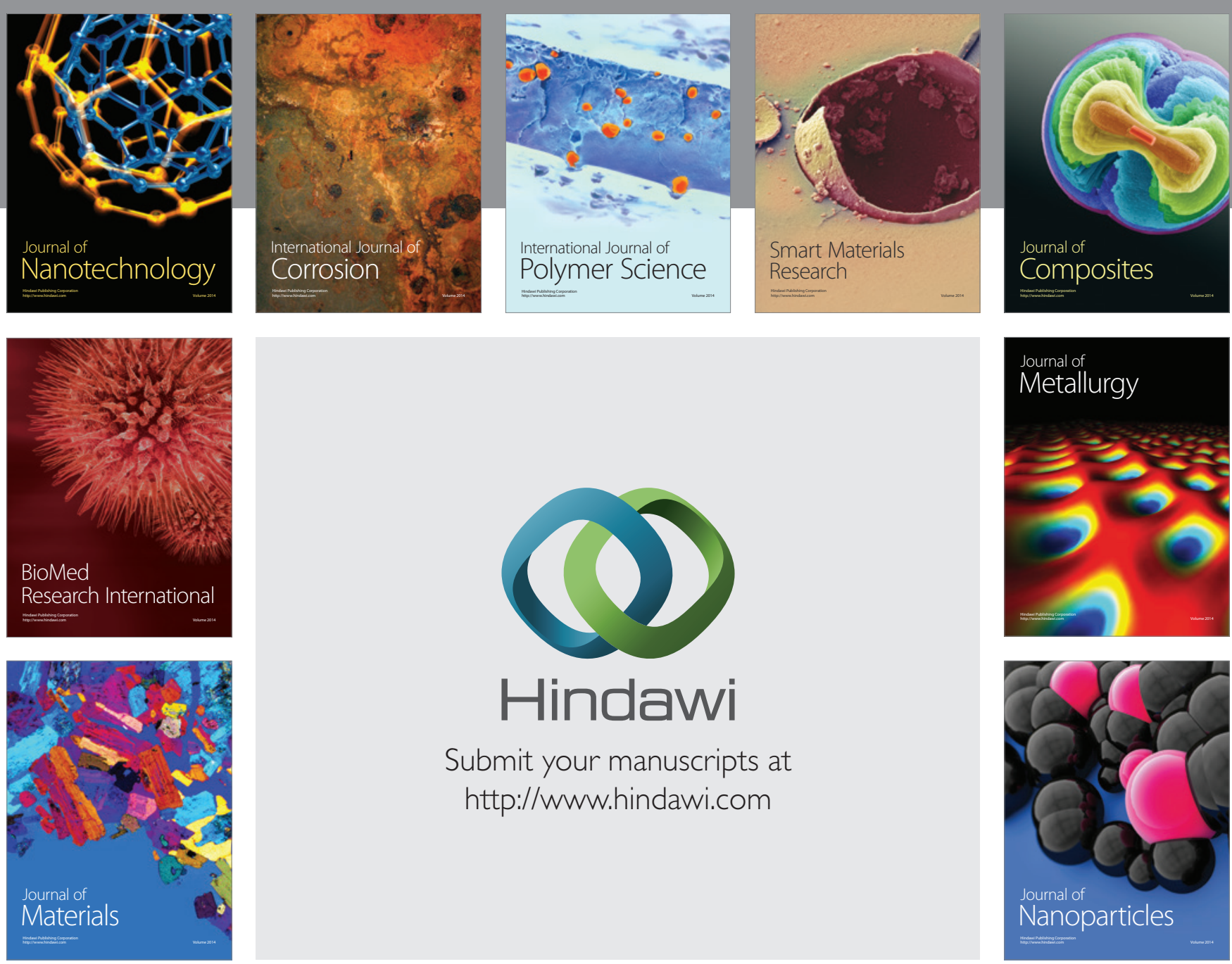

Submit your manuscripts at http://www.hindawi.com
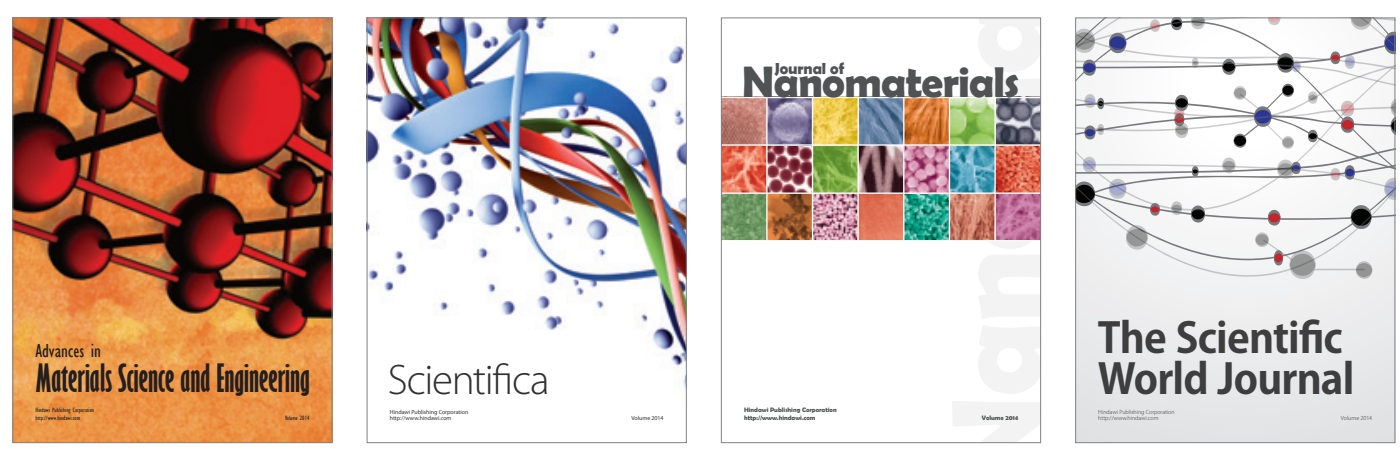

\section{The Scientific World Journal}
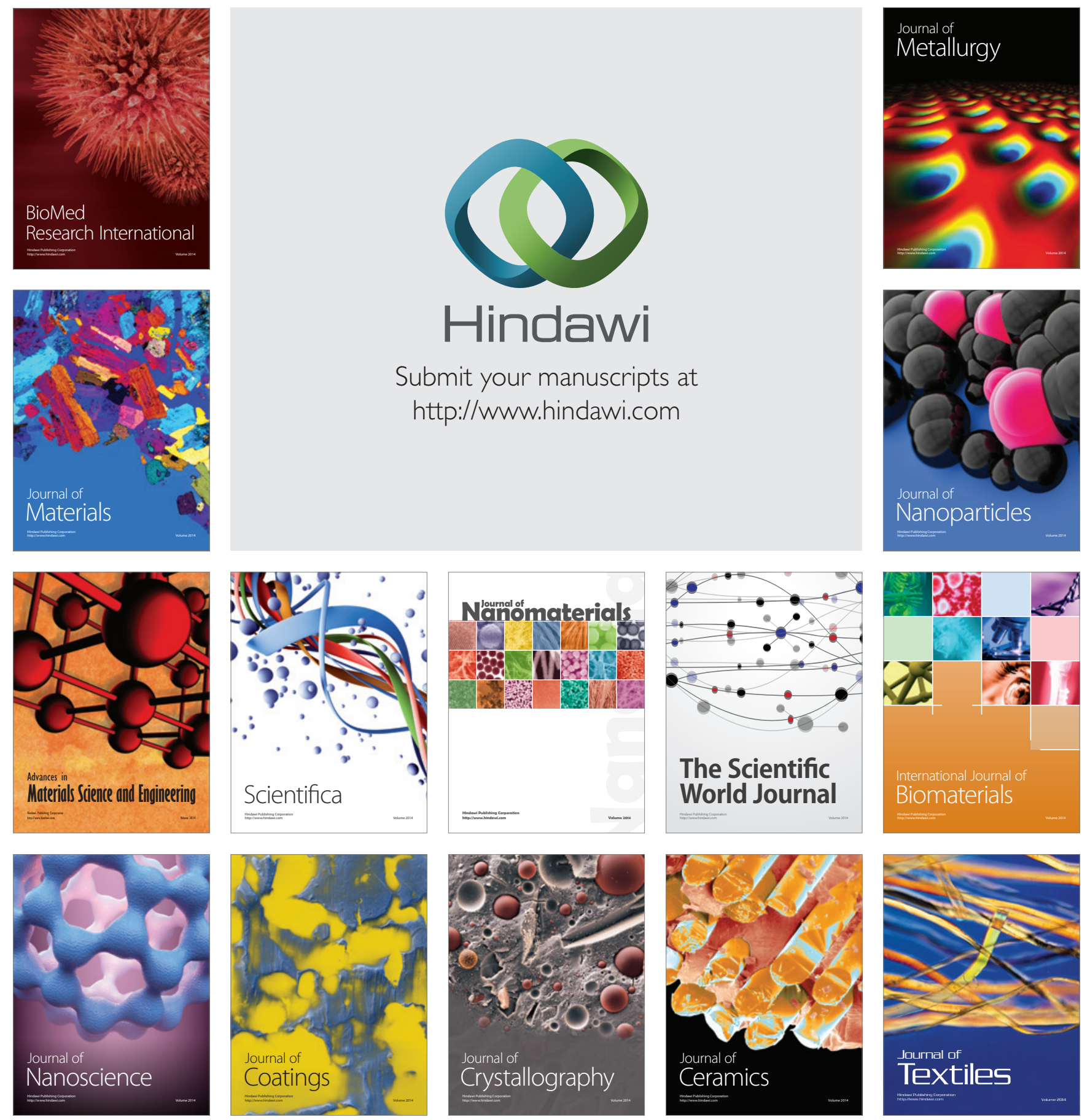